\title{
Improved Sectioning of High-Impact Polystyrene and Styrene/Acrylate Latex Using an Oscillating Diamond Knife for Transmission Electron Microscopy
}

\author{
J.D. Harris* and J.S. Vastenhout** \\ * Analytical Sciences, The Dow Chemical Company, 1897 Building, Midland, MI 48667 \\ ** Analytical Sciences, Dow Benelux B.V., HERBERT H. DOWWEG 5, Terneuzen, NL \\ 4530 AA, Netherlands
}

It is widely known that ultramicrotomy leads to compression of the ultra-thin sections. It has been found that reducing the knife angle from $45^{\circ}$ to $35^{\circ}$ leads to a reduction in compression [1]. Recent efforts to further reduce the compression of ultra-thin sections have led to the invention of an oscillating diamond knife [2].

The newly developed ultra sonic ${ }^{\mathrm{TM}}$ oscillating diamond knife from Diatome Ltd. was used to prepare ultra-thin sections for transmission electron microscopy (TEM). Two examples, high-impact polystyrene (HIPS) and styrene/acrylate (S/A) latex, were chosen for this report to demonstrate the advantages of the $35^{\circ}$ oscillating diamond knife.

Typically when cut with a standard diamond knife, this particular HIPS material shows particle deformation in the larger rubber particles (fig. 1). Compression of the rubber particles is also observed throughout and was measured to be approximately $25 \%$ by light microscopy. The S/A latex sample presents its own challenges for microtomy. First off, the dried latex must be embedded into an epoxy that will not react with it. Tests conducted found Pacer Industries two part Z-Poxy ${ }^{\mathrm{TM}}$ resin to be the best choice for this material [3]. The only drawback to using this epoxy is that is cures slightly softer than most, resulting in highly compressed sections (fig. 2).

The use of the new Diatome ultra sonic ${ }^{\mathrm{TM}}$ oscillating diamond knife has been found to further reduce and almost eliminate section compression. For these two materials, the overall particle morphology was greatly preserved as particles appeared more round and less elongated. The ultra-thin sections made with the oscillating diamond knife were also thinner, and no thickness differences were noticed.

\section{References}

[1] Jesior, J.-C., Scanning Microscopy (Suppl.3) (1989) 147-153.

[2] Studer, D. and Gnägi, H., Journal of Microscopy 197 (2000) 94-100.

[3] Sundberg, D.C. and Stubbs, J.M., Polymer 46 (2005) 1125-1138. 


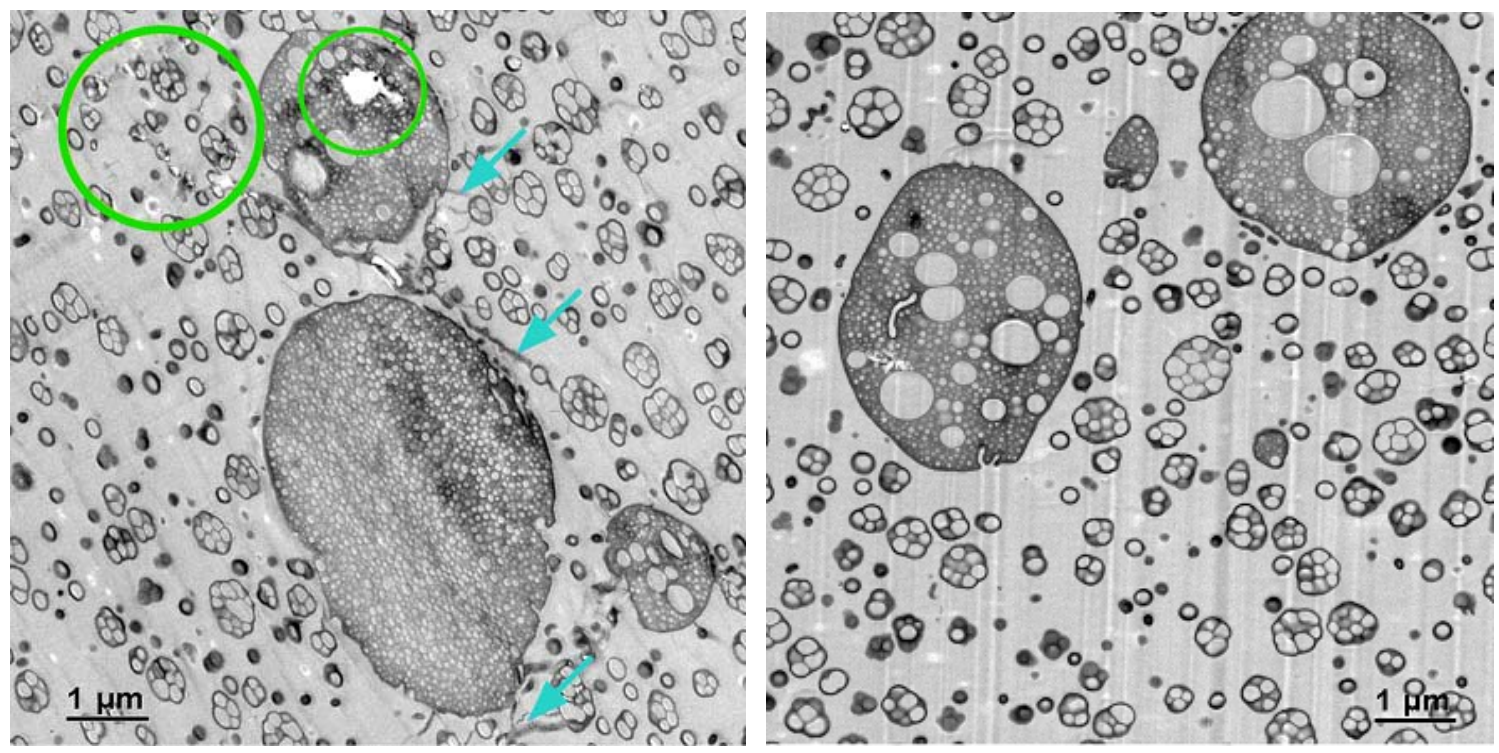

Fig. 1. TEM image of HIPS sample cut with a standard diamond knife (left) showing deformation of the rubber particles (circled in green), crazing (blue arrows) and compression. The morphology is better preserved when using the oscillating knife (right).
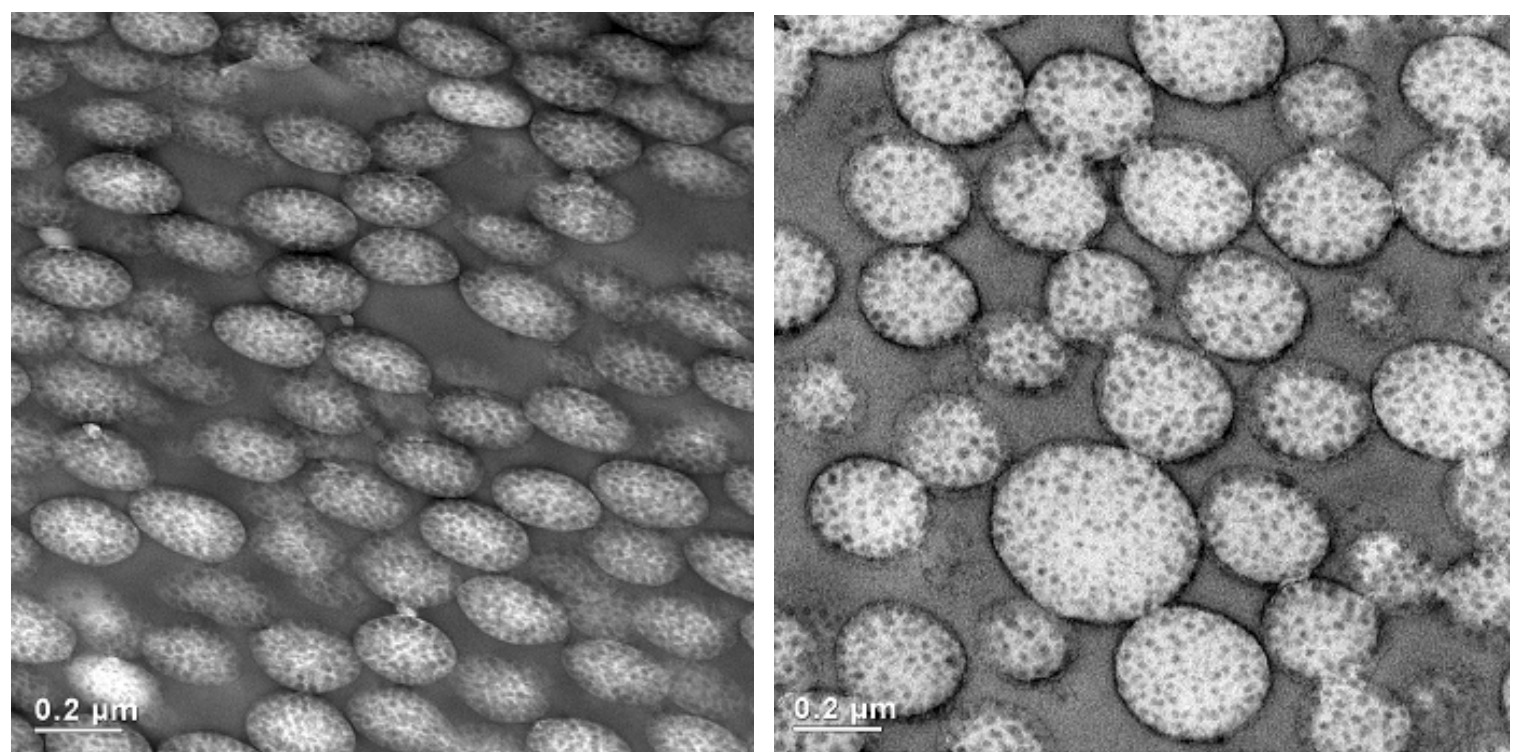

Fig. 2. The S/A latex sample on the left was cut with a standard knife and resulted in highly compressed sections. The same block face was then cut with an oscillating knife which resulted in compression free sections and truer round particles. 